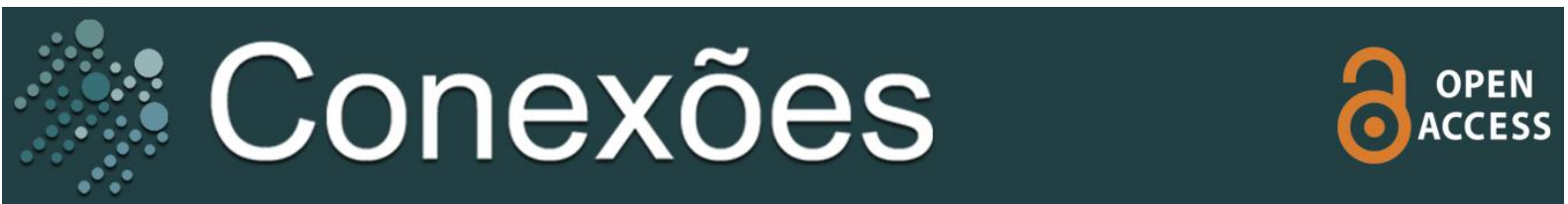

Artigo Original

\title{
A Educação Física na Área das Linguagens e as relações com a BNCC em tempos de distanciamento social
}

\author{
Physical Education in the Language Area and relations with BNCC in times of \\ social distance
}

\section{La Educación Física en el Área del Lenguaje y las relaciones con la BNCC en tiempos de distanciamiento social}

\author{
Jeniffer Da Silva Bielavski ${ }^{1}$ \\ Nicolas Fernandes ${ }^{1}$ \\ Francine Muniz Medeiros ${ }^{1}$ \\ Roseli Belmonte Machado ${ }^{1}$ \\ Denise Grosso da Fonseca ${ }^{1}$
}

\begin{abstract}
RESUMO
Objetivo: Este estudo trata da Educação Física na Área das Linguagens durante as aulas remotas. Seu objetivo foi compreender como ocorre a organização das aulas de Educação Física, de forma interdisciplinar, com os demais componentes da Área das Linguagens; e quais relações se estabelecem junto a Base Nacional Comum Curricular (BNCC), no Rio Grande do Sul, frente ao cenário do ensino remoto emergencial, consequente à pandemia de COVID-19. Métodos: De viés qualitativo, realizada com professores de Educação Física atuantes na Educação Básica do Estado do Rio Grande do Sul, através de envio de questionário pelo Formulário Google. A análise das informações indicou duas categorias principais: Educação Física enquanto componente da Área das Linguagens em tempos de distanciamento social e utilização da BNCC pelos professores de Educação Física durante o distanciamento social. Considerações finais: Foi possível identificar que os professores participantes da pesquisa encontraram diversas dificuldades no enfrentamento dos novos desafios impostos pelo distanciamento social. Sobretudo, na forma de planejar e desenvolver um trabalho coletivo com as demais disciplinas da Área das Linguagens, assim como a necessidade de adaptações para que se mantenha um trabalho apoiado na Base Nacional Comum Curricular nas aulas de Educação Física.
\end{abstract}

Palavras-chave: Educação Física. Distanciamento Físico. Educação: linguagens. Base Nacional Comum Curricular.

\footnotetext{
1 Universidade Federal do Rio Grande do Sul. Escola de Educação Física, Fisioterapia e Dança. Grupo de Estudos em Docência e Avaliação em Educação Física, Porto Alegre - RS, Brasil.
}

\section{Correspondência:}

Jeniffer da Silva Bielavski. Escola de Educação Física, Fisioterapia e Dança/UFRGS, Rua Felizardo, 750, Lapex, sala 210, Jardim Botânico, Porto Alegre - RS, CEP 90690-200. Email: bielavski@hotmail.com 


\begin{abstract}
Objective: This study investigates Physical Education in the Language Area during remote classes. The objective was to understand how the organization of Physical Education classes occurs, in an interdisciplinary way, with the other components of the Language Area; and what relationships are established with the National Common Curricular Base (BNCC), in Rio Grande do Sul, in face of emergency remote teaching, consequent to the COVID-19 pandemic. Methods: A qualitative research, carried out with Physical Education teachers of Basic Education in the State of Rio Grande do Sul, sending a questionnaire through the Google Form. The analysis of the information indicated two main categories: Physical Education as a component of the Language Area in times of social distance and use of BNCC by Physical Education teachers during social distance. Final considerations: It was identified that the teachers participating in this research had many difficulties in addressing the new challenges imposed by social distance. Mainly, in the form of planning and developing a collective work with the other disciplines of the Language Area and in the need to adapt a work supported by the Common National Curricular Base for Physical Education classes.
\end{abstract}

Keywords: Physical Education. Physical Distancing. Education - Language. National Common Curricular Base.

\title{
RESUMEN
}

Objetivo: Este estudio investiga la Educación Física en el Área del Lenguaje durante las clases a distancia. El objetivo fue comprender cómo se da la organización de las clases de Educación Física, de forma interdisciplinar, con los demás componentes del Área de Lenguaje; y qué relaciones se establecen con la Base Curricular Común Nacional (BNCC), en Rio Grande do Sul, frente a la enseñanza remota de emergencia, consecuente a la pandemia de COVID-19. Métodos: Se trata de una investigación cualitativa, realizada con profesores de Educación Física de Educación Básica en el Estado de Rio Grande do Sul, enviando un cuestionario en el Formulario de Google. El análisis de la información indicó dos categorías principales: Educación Física como componente del Área de Lenguaje en tiempos de distancia social y uso de BNCC por parte de los docentes de Educación Física durante la distancia social. Consideraciones finales: Se identificó que los docentes que participaron en esta investigación tuvieron muchas dificultades para abordar los nuevos desafíos que impone la distancia social. Principalmente, en la forma de planificar y desarrollar un trabajo colectivo con las demás disciplinas del Área de lenguaje y en la necesidad de adecuar un trabajo apoyado en la Base Curricular Común Nacional para las clases de Educación Física.

Palabras Clave: Educación física. Distanciamiento Físico. Educación - Lenguaje. Base Nacional Común Curricular. 


\section{INTRODUÇÃO}

Esta pesquisa nasce da necessidade de compreender o movimento que ocorreu nas escolas do Rio Grande do Sul, mais especificamente com a Educação Física Escolar, que assim como outros componentes curriculares, foi afetada pela pandemia de COVID-19 com a suspensão das aulas presenciais. A interrupção das atividades presenciais nas instituições escolares segue as normas da Organização Mundial da Saúde para diminuição do contágio pelo vírus, medida essa adotada pelo mundo todo. Entretanto, no Brasil, além das preocupações com as questões sanitárias, estados e municípios precisaram enfrentar o negacionismo do Governo Federal. Houve pressão para que as instituições de ensino não fossem fechadas. E após o fechamento, em março, logo em abril a pressão passou a ser pela volta das aulas presenciais, contrariando recomendações da OMS.

Nas últimas décadas, nunca tantos países ao redor do mundo fecharam escolas e universidades ao mesmo tempo. No Brasil, todos os 26 Estados do país e o Distrito Federal estão adotando medidas para combater a proliferação do novo Coronavírus. Aulas em escolas públicas de todo o país foram suspensas. Isso resultou em mais de 1,1 milhão de alunos e 58 mil professores do Ensino Fundamental e Ensino Médio, que foram afastados das escolas em meados de 2020 (HIROSE, 2020).

A Educação foi obrigada a se reinventar em tempos de pandemia e distanciamento social. Neste momento, trocamos a sala de aula pelo confinamento das nossas casas, aprendendo com os mesmos professores, mas com diferentes formatos de aulas, agora intermediados por uma tela. Ou seja, as aulas de Educação Física que ocorriam, anteriormente, nas quadras esportivas e/ou salas de aula, com experiências e contato entre os alunos, foram interrompidas. Vale notar que este é um componente curricular marcadamente identificado pelo saber fazer, pelas vivências e experimentações corporais (ANVERSA et al., 2017; LAZZAROTTI FILHO et al., 2015).

Paulo Freire (1977, p. 69) já nos dizia que "educação é comunicação, é diálogo, na medida em que não há transformação do saber, mas um encontro de interlocutores que buscam a significação dos significados". Então, quando esse processo é alterado, e mediado pelas tecnologias, nossas formas de interação e de comunicação mudam. Portanto, o domínio das tecnologias tornou-se essencial para manter esse processo e é um desafio não apenas para os professores, mas para toda a comunidade escolar.

O uso da tecnologia nas salas de aula, assunto que há algum tempo vem sendo discutido, intensificou-se para mediar o processo do ensino remoto. Neste sentido, torna-se importante salientar que as aulas estão sendo desenvolvidas de diferentes formas com o auxílio de diversas ferramentas tecnológicas, porém as mesmas, em sua maioria, necessitam que estudantes e professores tenham acesso 
à internet e aparelhos tecnológicos para a transmissão e acompanhamento do trabalho. Sendo assim, é preciso lembrar que um a cada quatro brasileiros não tem acesso à internet, o que, em números totais, representa cerca de 46 milhões (AGÊNCIA BRASIL, 2020a). Outra pesquisa, publicada na revista Estado de Minas em fevereiro de 2019 mostrou que 17\% da população brasileira não tem acesso a nenhum aparelho tecnológico (DINO, 2019).

Embora as tecnologias possam ser uma ferramenta explorada pelos professores, os desafios ainda são grandes para transformar, por exemplo, o celular em ferramenta para estudo. Além das dificuldades de acesso às plataformas de ensino e do grande número de brasileiros sem acesso à internet, acrescentam-se os brasileiros que têm acesso precário à internet, subindo para 70 milhões (SOPRANA, 2020). Há uma maior desigualdade social dos brasileiros quando é feito o recorte das classes $D$ e $E$. Dos que têm acesso à rede, $85 \%$ utilizam a internet só pelo celular e com pacotes limitados. Além disso, as antenas de celulares devem enviar sinal para 1.500 aparelhos. Nas periferias, esse número pode chegar a 12 vezes mais aparelhos conectados a uma mesma antena, tornando o sinal muito fraco. Mesmo os brasileiros que têm algum acesso à internet enfrentam diversas outras dificuldades, o que muitas vezes torna as aulas digitais inviáveis (AGÊNCIA BRASIL, 2020b).

Além disso, há uma particularidade muito presente nas aulas de Educação Física, que está relacionada às atividades planejadas e desenvolvidas visando o movimento corporal, que segundo a BNCC (BRASIL, 2017, p. 214) são textos culturais passíveis de leitura e produção e que não descartam a reflexão sobre o movimento, sendo, na maioria dos casos, o principal trabalho desenvolvido pelos professores nas escolas, nas aulas presenciais. Neste trabalho, além de todas dificuldades que os outros componentes curriculares enfrentam, como a tecnologia, a internet, as ferramentas, o planejamento e tantos outros, os professores de Educação Física tem manifestado dificuldades em desenvolver suas aulas de forma remota, quando as mesmas são compostas por atividades que contemplem o movimentar-se, dada também a necessidade de adequação às realidades apresentadas de cada estudante dentro de suas casas, bem como dos espaços e estrutura das residências dos professores.

Embora a necessidade de um modo de ensino emergencial tenha mostrado uma gama de tecnologias e ferramentas que crescem a cada dia e facilitam o trabalho, inclusive algumas que podem ser adotadas para o pós-pandemia, é preciso compreender as diferentes realidades que se encontram país afora. Nessa perspectiva, se torna importante atentar para as desigualdades sociais e econômicas que podem impossibilitar o fácil acesso às diversas tecnologias e ferramentas que emergem junto ao ensino de forma remota.

Tendo em vista esse novo cenário e essas novas formas em que as aulas são ministradas, compreendemos que é importante ouvir o professor que está atuando 
diretamente neste momento de desafios. Nesse sentido, este estudo se debruça a ouvir os docentes, tendo como objetivo compreender como ocorre a organização das aulas de Educação Física, de forma interdisciplinar, com os demais componentes da Área das Linguagens; e quais relações se estabelecem junto a Base Nacional Comum Curricular (BNCC), no Rio Grande do Sul, frente ao cenário do ensino remoto emergencial, durante o distanciamento social consequente à pandemia de COVID-19.

\section{CAminhos de pesquisa}

O presente estudo percorre os caminhos da abordagem qualitativa. Optar por um estudo dessa natureza, de acordo com Gatti e André (2013) diz respeito a um mergulho em situações em que são produzidos os sentidos e significados do que se procura conhecer, buscando uma compreensão que aproxime o real com as formas de representação e ação. Na esteira do pensamento de autores que trabalham com essa abordagem, consideramos que olhar para nosso objeto num desenho qualitativo nos traz a possibilidade de compreender o momento educacional atual e o modo como a Educação Física está implicada nele.

Dentro da abordagem de pesquisa qualitativa, realizamos um estudo de cunho exploratório, procurando, para dar conta do objetivo proposto, conversar com professores de Educação Física que estivessem atuando nas escolas gaúchas no momento do distanciamento social. Nesse sentido criamos um questionário online na plataforma de formulários Google, inicialmente encaminhado aos professores atuantes na Educação Básica que estivessem exercendo a profissão durante este período e que realizaram curso de extensão na Universidade. Após, solicitamos que os docentes divulgassem a pesquisa a outros colegas e também divulgamos a pesquisa em redes sociais, destacando as características dos sujeitos que poderiam responder: professores de Educação Física atuantes na Educação Básica durante o ensino remoto. O questionário foi divulgado no dia $1^{\circ}$ de maio de 2020 e recebeu retorno até o dia 10 de maio do mesmo ano. Nele continham vinte questões, que variaram entre objetivas e dissertativas e que abordavam diversos questionamentos sobre a prática pedagógica. Importa dizer que este estudo foi realizado mediante análise e aprovação do projeto de pesquisa $n^{\circ} .1 .123 .640$, pelo Comitê de Ética da UFRGS.

Foi encaminhado a todos os participantes um termo de adesão com os respectivos esclarecimentos e cuidados éticos. Todos os questionários estão de posse dos pesquisadores e comprovam que os sujeitos que responderam atendem aos critérios da pesquisa.

Ao final desse processo, recebemos 43 formulários respondidos. Desses, recebemos respostas de onze professores que atuam na rede estadual de ensino, de doze que atuam em escolas privadas e de vinte professores que atuam nas 
redes municipais de ensino, oriundos da capital do Estado, Porto Alegre, e de outras 14 cidades gaúchas. Esses docentes atuam no Ensino Fundamental, no Ensino Médio e na Educação Infantil, sendo que a maioria atua em mais de uma modalidade de ensino.

As respostas ao questionário foram agrupadas e organizadas de acordo com suas respectivas perguntas, em seguida realizamos, para este estudo, a seleção das respostas das seguintes perguntas: "Acontecem relações (planejamentos, reuniões, tarefas, avaliação etc.) entre a Educação Física e a Área das Linguagens?", "Você estava trabalhando com a BNCC?" e "Como está o trabalho com a BNCC agora?", a fim de cumprir com o objetivo principal deste estudo, que está pautado em compreender como ocorre o planejamento das aulas de Educação Física, de forma interdisciplinar, com os demais componentes da Área das Linguagens, e quais relações se estabelecem junto a Base Nacional Comum Curricular (BNCC). Por fim, para organizar a discussão, durante a análise das respostas dos professores, emergiram duas categorias de análise, quais sejam: a) Educação Física enquanto componente da Área das Linguagens em tempos de distanciamento social e b) Utilização da BNCC pelos professores de Educação Física durante o distanciamento social.

\section{EdUCAÇÃO FÍSICA COMO COMPONENTE DA ÁREA DAS LINGUAGENS EM TEMPOS DE DISTANCIAMENTO SOCIAL}

Devido às diversas mudanças atribuídas à Educação Física escolar com o passar dos anos, alguns documentos, como os Parâmetros Curriculares Nacionais para o Ensino Médio ratificam a Educação Física na Área de Linguagens, Códigos e suas Tecnologias, juntamente com as disciplinas Língua Portuguesa, Artes, Informática, Literatura e Língua Estrangeira Moderna. Uma das justificativas para essa inserção é pelo entendimento do corpo e dos movimentos como um meio de comunicação (BRASIL, 2000).

Para Fonseca et al. (2015, p. 116), as mudanças que ocorreram com a Educação Física com o passar dos anos estão diretamente associadas com "estratégias para estabelecer um ideal e um modo de vida". Ainda para os autores, a inclusão do componente curricular Educação Física na Área das Linguagens faz parte, também, de um ideário social, de um modo de vida neoliberal. Isto evidencia uma pretensão ligado à articulação dos sujeitos uns com os outros, em um trabalho em conjunto, característica desta sociedade em que vivemos.

Já na BNCC, o currículo também está organizado por áreas de conhecimento. Essas áreas, como bem aponta o Parecer CNE/CEB no 11/2010, "favorecem a comunicação entre os conhecimentos e saberes dos diferentes componentes curriculares" (BRASIL, 2010). As áreas se intersectam na formação dos alunos, mantendo especificidades e saberes próprios construídos e sistematizados nos diversos componentes. Neste sentido, cada área do conhecimento explicita seu 
papel na formação integral dos alunos e destaca particularidades considerando tanto as características dos alunos, quanto às especificidades e demandas pedagógicas das diferentes fases da escolarização (BRASIL, 2018).

Nas áreas que abrigam mais de um componente curricular, caso da Educação Física, são definidas competências específicas de cada componente a serem desenvolvidas pelos alunos ao longo da escolarização. Embora cada componente trabalhe com competências específicas, o currículo por áreas de conhecimento promove destaque quanto aos conteúdos, competência e habilidades comuns entre os componentes curriculares. A organização por áreas, como bem aponta o Parecer CNE/CP no 11/2009

não exclui necessariamente as disciplinas, com suas especificidades e saberes próprios historicamente construídos, mas, sim, implica o fortalecimento das relações entre elas e a sua contextualização para apreensão e intervenção na realidade, requerendo trabalho conjugado e cooperativo dos seus professores no planejamento e na execução dos planos de ensino (BRASIL, 2009).

Nos PCNs+ se compreende a Área por meio da ideia "de que o todo é maior que a soma das partes. Por isso, pode-se afirmar que também a área de Linguagens, Códigos e suas Tecnologias - como as duas outras - é mais que uma simples reunião de especialidades ou de disciplinas afins". (BRASIL, 2002, p. 26). Nesse sentido, o documento defende que o currículo por áreas respeita a diversidade de cada disciplina ou componente curricular, porém conduz a aprendizagem dos conceitos de forma que possam ser realizadas integradamente.

Sendo assim, considerando que a Educação Física está atualmente inserida na Área das Linguagens e de acordo com os documentos citados anteriormente, pensado em uma concepção de área de conhecimento pautada pela organização de um currículo mais interdisciplinar, é notável a necessidade de ações que deem a possibilidade aos docentes para planejarem um trabalho conjunto, visando o desenvolvimento das habilidades e competências necessárias. Dessa forma, reuniões, encontros, debates, estudos, são algumas ações que podem contribuir para o diálogo entre os componentes curriculares da área e seus docentes. Para Fonseca et al. (2015, p. 107) o trabalho interdisciplinar desenvolvido por áreas de conhecimento tem sido um dos propósitos da educação escolar, nesse aspecto, os autores destacam a necessidade de:

Discutir a forma como serão abordados os conteúdos de cada componente de modo que seja preservada a especificidade da disciplina e, ao mesmo tempo, seja possibilitado o diálogo e seja promovido o compartilhamento entre os diferentes componentes (FONSECA et al. 2015, p. 107).

Porém, através do questionário, foi possível identificar certa dificuldade dos professores em planejarem e desenvolverem de forma conjunta com as demais 
disciplinas da Área no cenário atual das aulas remotas. Com exceção de alguns professores que relataram estarem se reunindo virtualmente com os docentes das outras disciplinas da Área e realizando planejamentos em conjunto, houve também relatos de que nas escolas em que lecionam, está recém iniciando este movimento e outros que relatam estarem realizando seu planejamento de forma individual.

Nesse sentido, podemos observar algumas situações relatadas pelos professores a seguir:

"Antes do período de isolamento o espaço para essas discussões era reduzido, agora ele não existe" (Professor $U$ )

"Não estão ocorrendo reuniões de Planejamentos. Cada Professor está fazendo o seu planejamento e postando as atividades" (Professor M)

"Cada professor elabora individualmente suas atividades e propostas de aula, como já era feito anteriormente" (Professor 6)

Este último traz uma situação em que, na sua escola, não havia o planejamento por Áreas nem anteriormente à pandemia. Nesta perspectiva, chamamos a atenção para o trabalho disciplinar de cada componente curricular, deixando de lado a concepção de área que se debruça na ideia de um currículo interdisciplinar, quando basicamente cada disciplina desenvolve o seu planejamento sem qualquer relação com as demais disciplinas da área. Para Fazenda (2011), a interdisciplinaridade está pautada na relação de reciprocidade e de mutualidade baseada na substituição de uma concepção fragmentária para unitária do ser humano, onde todo o conhecimento é igualmente importante. Além disso, para a autora a interdisciplinaridade não pode ser um fim metodológico, pois "nem se ensina e nem se aprende, se vive, se exerce e por esse motivo exige uma nova pedagogia, que segundo ela, é a da comunicação". (FAZENDA, 2011, p. 11).

Além disso, parte da dificuldade de se desenvolver um trabalho por áreas do conhecimento, mais especificamente no caso da Área das Linguagens em relação a Educação Física, se dá pela dificuldade de alunos, professores e também de outros membros inseridos na comunidade escolar, que não compreendem os conteúdos atribuídos a Educação Física. Conteúdos esses, relacionados com os conteúdos dos demais componentes da área. Além disso, parte do público citado anteriormente, visualizam uma maior relação com outras áreas de conhecimento, como por exemplo, as ciências da natureza, o que dificulta este trabalho interdisciplinar com os demais componentes da Área das Linguagens. Isso impacta no desenvolvimento das aulas, nas abordagens trabalhadas e na seleção dos conteúdos. Em estudo desenvolvido por Fonseca et al. (2017), as autoras destacam que a inserção da Educação Física na Área das Linguagens trouxe modificações para o fazer docente, antes identificado com áreas biologicistas, hoje apresentam dificuldades para compreender essa relação da Educação Física na área, privilegiando conteúdos de expressão corporal. Para Santos et al. (2012), 
compreender a Educação Física como componente da Área das Linguagens não se dá como uma tarefa simples, já que a disciplina não se limita unicamente ao elemento central da linguagem corporal, ou seja, não está restrita aos elementos que dialogam com a Área.

\section{Base Nacional Curricular Comum, educaÇão física e ensino remoto}

A Base Nacional Comum Curricular (BNCC), no caso do Ensino Médio, prevê incluir obrigatoriamente, estudos e práticas de Educação Física, Arte, Sociologia e Filosofia. As condições de estudos e práticas, bem como as alterações que vinham sendo propostas desde a Medida Provisória 746/2016, posteriormente sancionadas pela lei 13.415/2017, referentes à Reforma do Ensino Médio, tratam da obrigatoriedade do ensino de Educação Física, Arte, Sociologia e Filosofia, mas não as garantem como componentes curriculares a exemplo das demais disciplinas. Em contrapartida, de acordo com a Lei de Diretrizes e Bases da Educação Nacional (LDB, Lei 10.793/2003) a Educação Física consta como componente curricular obrigatório da Educação Básica.

De acordo com a LDB (Lei no 9.394/1996), a BNCC deve nortear os currículos e as propostas pedagógicas de todas as escolas públicas e privadas de Educação Básica em todo o Brasil. O documento estabelece os conhecimentos, as competências e as habilidades que os alunos precisam desenvolver ao longo da vida escolar.

No atual contexto, a BNCC foi analisada, buscando-se integrá-la aos demais artefatos que ajudam a compor o currículo das escolas brasileiras, apesar dos muitos questionamentos acerca do modo como foi produzida e da pouca profundidade dada à sua versão final, que desconsiderou o processo de escuta e coparticipação de distintas instâncias e instituições ligadas à educação no país, o que, em consequência, traz limitações na versão relativa ao Ensino Médio, como por exemplo, a falta de habilidades e competências de forma mais detalhada para a etapa. Dessa forma, cabe salientar, que o documento prevê que o que foi desenvolvido no Ensino Fundamental seja aprofundado durante o Ensino Médio:

A Base Nacional Comum Curricular da área de Linguagens e suas Tecnologias busca consolidar e ampliar as aprendizagens previstas na BNCC do Ensino Fundamental nos componentes Língua Portuguesa, Arte, Educação Física e Língua Inglesa (BRASIL, 2018, p. 481).

A Educação Física é reafirmada na BNCC como constituinte da Área das Linguagens, em articulação com Língua Portuguesa, Arte e Língua Inglesa. Nessa perspectiva, "[...] tematiza as práticas corporais em suas diversas formas de codificação e significação social, entendidas como manifestações das possibilidades expressivas dos sujeitos, produzidas por diversos grupos sociais no decorrer da história". (BRASIL, 2018, p. 213). 
A BNCC estabelece a aprendizagem por meio do desenvolvimento das habilidades e competências, porém, considerando o contexto atual, em que os alunos estão longe das salas de aula, e que pelo menos 4,8 milhões de pessoas em todo o Brasil não tem acesso à internet, e mais alguns milhões que tem um acesso precário ou não tem equipamento adequado, se torna um desafio cada vez maior manter algum vínculo com os alunos durante esse período de isolamento social (AGÊNCIA BRASIL, 2020). Segundo dados trazidos pelo Secretário-Geral das Nações Unidas, António Guterres (2020), diante da pandemia de COVID-19, até meados de julho, as escolas estavam fechadas em mais de 160 países, afetando mais de 1 bilhão de estudantes. Enquanto no Brasil, cerca de 35 milhões de crianças e adolescentes estão fora das salas de aula (E-DOCENTE, 2020).

Para a Educação Física, no Ensino Fundamental, anos iniciais e finais, está previsto que sejam trabalhadas as seguintes unidades temáticas: Brincadeiras e jogos, Esportes, Ginásticas, Danças, Lutas e Práticas corporais de aventura. Através dessas práticas corporais, o componente curricular tem por seus objetivos principais propiciar ao aluno o acesso a conhecimentos e experiências que ele não teria fora do ambiente escolar, bem como assegurar a ampliação da sua consciência em relação aos seus movimentos e também dos recursos para o seu cuidado e dos demais, além de desenvolver autonomia para a apropriação e também utilização da cultura corporal de movimento para diferentes finalidades humanas. (BRASIL, 2018).

O trabalho com a BNCC tem se mantido, como relata a maioria dos professores pesquisados, mas com adaptações na aplicação. Todavia, percebemos que manter o vínculo com os alunos se tornou um dos principais elementos para a realização das atividades remotas:

\footnotetext{
"Tentando se aproximar da proposta inicial do ano onde estava planejado e articulado com o documento, mas nesse momento o vínculo está priorizado, além das habilidades e competências." (Professor $\mathrm{HH}$ )
}

Segundo a BNCC (2018, p. 213), a Educação Física oferece uma série de possibilidades para enriquecer a experiência na Educação Básica, permitindo o acesso ao que chama de "um vasto universo cultural". Esse universo cultural é compreendido como "saberes corporais, experiências estéticas, emotivas, lúdicas e agonistas, que se inscrevem, mas não se restringem, à racionalidade típica dos saberes científicos que, comumente, orienta as práticas pedagógicas na escola". Assim, o "universo cultural" além da vivência, a experiência efetiva das práticas corporais também oportunizaria aos alunos participar, de forma autônoma, em contextos de lazer e saúde (BRASIL, 2018, p. 213).

$\mathrm{Na}$ impossibilidade de seguir neste caminho em que as vivências são priorizadas na BNCC os professores buscam alternativas às aulas práticas. 
Cumprindo as determinações de estados e municípios, os professores estão tentando adequar as aulas para o ensino remoto, optando em muitos casos por atividades predominantemente conceituais, o que traz preocupação a eles. Importa destacar que, embora outros documentos, tais como os Parâmetros Curriculares Nacionais, trouxessem a distinção dos conteúdos em conceituais, procedimentais e atitudinais, isso não ocorre na BNCC.

Todavia, ao analisarmos as unidades temáticas presentes no documento para a Educação Física no Ensino Fundamental, como Brincadeiras e Jogos, Esportes, Lutas, Ginásticas, Danças, e olharmos para o que está especificado em habilidades, percebemos que as dimensões atitudinais, conceituais e corporais estão presentes. Dentro dessa concepção, podemos pensar que problematizar o movimento humano não se limita a um deslocamento espaço-temporal. Além disso, os professores parecem indicar que as escolas apresentam diversas dificuldades na implementação e adequação deste modelo de ensino remoto, quando declaram:

"Estou tentando seguir os conteúdos propostos pela BNCC mas com algumas adaptações em virtude do momento que estamos vivendo." (Professor PP)

Outra dificuldade enfrentada é com a progressão dos conteúdos:

"Como não podemos iniciar novos conteúdos ficou um pouco difícil." (Professor B)

Tudo isso, somado com as questões econômicas, que se desdobram nas condições de acesso já comentadas, contribui para uma carência ainda maior no desenvolvimento das competências e habilidades apresentadas na BNCC.

Diante das dificuldades relatadas em relação à comunicação com o aluno, os docentes destacam outro problema no desenvolvimento do trabalho com a BNCC, que seria o fato de algumas competências não serem contempladas no ensino remoto, como relatam os professores nas seguintes falas:

"Buscando adequar com a BNCC, pois algumas habilidades e competências não são contempladas no ensino remoto." (Professor $\mathrm{H})$

"Tentando adaptar para a realidade "on-line" (Professor C)

Nesse sentido, podemos observar que os professores têm se afastado dos documentos norteadores da Educação como a BNCC, por exemplo, justamente pelo momento atípico ao qual estamos submetidos. Sendo assim, ocorre uma grande dificuldade de adaptar os conteúdos, habilidades e competências destes documentos para o planejamento das aulas no formato remoto. Deste modo, os professores têm buscado conteúdos que possam contemplar questões relacionadas à pandemia. 
Além da dificuldade do impasse evidente no planejamento das aulas, podemos identificar outras situações em relação ao ensino remoto que prejudicam a docência. Destaca-se a carga horária excedente, necessitando o professor estar disponível nas plataformas on-line para sanar dúvidas, auxiliar, explicar, enviar as tarefas, receber e corrigir as mesmas, sendo de forma digital ou física, levando e buscando as tarefas nas escolas para que as famílias, que não conseguem acompanhar on-line, possam ter acesso. Além disso, também a necessidade de se familiarizar com as plataformas digitais, com as tecnologias, ter acesso a dispositivos e internet, por exemplo, são questões aliadas ao "novo normal" que, além de novidade, se torna dificuldade para a maioria dos professores no desenvolvimento da sua docência.

Para Saraiva et al. (2020, p. 17) essas questões estão relacionadas com a exaustão docente em tempos de pandemia

A docência nos tempos de pandemia é uma docência exausta, ansiosa e preocupada. Que quer acertar, mas que avança no meio da incerteza e da adversidade - e que não tem a menor ideia do caminho. Como todos, os professores estão imersos em uma névoa e seguem através dela, buscando fazer o melhor, mas sem garantias.

Nesse sentido, podemos perceber que os professores se sentem "perdidos" levando em consideração que a situação atual não tem precedentes na Educação Básica de todo o mundo. Sendo assim, a docência em Educação Física tem enfrentado diversas dificuldades em trilhar os novos caminhos para a educação no momento atual.

\section{RefLeXões e Considerações}

Considerando o momento atípico que estamos vivendo atualmente, compreendemos o ensino remoto, de forma on-line, como um recurso importante nesse cenário, com o objetivo de manter as aulas, assim como o vínculo dos alunos e professores com as escolas. Porém, devido às grandes dificuldades já citadas anteriormente, como por exemplo, a disponibilidade de acesso à internet, às tecnologias e as demais adversidades enfrentadas pelos professores em relação ao desenvolvimento de sua prática pedagógica, entendemos que o ensino remoto não substitui o ensino que é desenvolvido presencialmente.

De acordo com o objetivo principal do estudo, que estava pautado em compreender como ocorre a organização das aulas de Educação Física, de forma interdisciplinar, com os demais componentes da Área das Linguagens, e quais as relações se estabelecem junto a BNCC, no Rio Grande do Sul, frente ao cenário do ensino remoto emergencial durante o distanciamento social consequente à pandemia de COVID-19, foi possível observar que há uma dificuldade em realizar e manter o planejamento por áreas de conhecimento de forma interdisciplinar, 
mais especificamente na Área das Linguagens, em que está inserida a Educação Física. Além disso, observamos que os documentos norteadores da Educação Básica, mesmo que haja a possibilidade de serem ressignificados no cotidiano escolar, nem sempre são utilizados no dia a dia dos planejamentos escolares. E, atualmente, há uma maior dificuldade de utilização durante o ensino remoto, pois, como nos foi relatado, antes desse período de distanciamento o tempo de planejamento era precário e hoje se tornou praticamente inexistente.

Segundo Saraiva et al. (2020, p. 13), o trabalho vai além da carga horária contratada e o professor encontra-se disponível nos três turnos para responder às perguntas e tirar dúvidas. Também há a necessidade de planejar atividades, enviar, e ainda ter tempo para receber e corrigir. Neste sentido, a oportunidade de planejamento conjunto poderia trazer solução para alguns dos tantos apontamentos anteriores, visto que, planejando dentro das áreas de conhecimento os professores poderiam trabalhar com as temáticas de forma interdisciplinar, que desenvolvidas nos diferentes componentes curriculares podem fazer mais sentido aos alunos.

Percebemos ainda que todas as dificuldades que envolvem a docência foram potencializadas devido a necessidade de se trabalhar através do ensino remoto. Dessa forma, visto que, não havendo precedentes parecidos com a situação atual, os docentes acabam tendo que redobrar sua jornada de trabalho para dar conta de desenvolver sua prática docente nos moldes atuais. Essas situações acabam gerando uma exaustão docente, como expressado por Saraiva et al. (2020) na obra a educação em tempos de COVID-19: ensino remoto e exaustão docente, citada neste estudo anteriormente.

Além de todas essas dificuldades ao enfrentar o ensino remoto, os professores se sentem ainda mais confusos e inseguros na sua prática docente quando, muitas vezes, não recebem nenhum retorno dos seus alunos. Visto que manter o vínculo entre escola e aluno é extremamente importante para o andamento do processo de ensino-aprendizagem. O diálogo e a troca de experiência sempre foram grandes aliados dos professores e, neste momento, aqueles que conseguem essa aproximação, efetivam uma possibilidade de analisar, refletir e ajustar sua prática docente.

Compreendemos que esse novo cenário não será permanente, e que apesar de todas as dúvidas e inseguranças é importante se pensar na educação para durante e pós pandemia. Nesse sentido, consideramos importante que estudos como este sejam desenvolvidos a fim de dar voz a parte dos protagonistas envolvidos diretamente neste novo cenário ao qual estamos inseridos, na intenção de que sejam desenvolvidas ações que auxiliem os mesmos enquanto este modelo de ensino esteja em evidência. 


\section{NOTAS}

\section{CONFLITOS DE INTERESSE}

Os autores não têm conflitos de interesse, incluindo interesses financeiros específicos e relacionamentos e afiliações relevantes ao tema ou materiais discutidos no manuscrito.

\section{Autoria e CoAutoria}

Os autores declaram que participaram de forma significativa na construção e formação desde estudo, tendo, enquanto autores, responsabilidade pública pelo conteúdo deste, pois contribuíram diretamente em sua publicação e satisfazem as exigências de autoria.

Jeniffer Da Silva Bielavski - Desenho metodológico (planejamento dos métodos para gerar os resultados); Supervisão (responsável pela organização e execução do projeto e da escrita do manuscrito); Coleta e tratamento dos dados (responsável pelos experimentos, pacientes, organização dos dados); Análise / interpretação (responsável pela análise estatística, avaliação e apresentação dos resultados); Levantamento da literatura (participou da pesquisa bibliográfica e levantamento de artigos); Redação (responsável por escrever uma parte substantiva do manuscrito).

Nicolas Fernandes - Desenho metodológico (planejamento dos métodos para gerar os resultados); Coleta e tratamento dos dados (responsável pelos experimentos, pacientes, organização dos dados); Análise / interpretação (responsável pela análise estatística, avaliação e apresentação dos resultados); Levantamento da literatura (participou da pesquisa bibliográfica e levantamento de artigos); Redação (responsável por escrever uma parte substantiva do manuscrito).

Francine Muniz Medeiros - Desenho metodológico (planejamento dos métodos para gerar os resultados); Coleta e tratamento dos dados (responsável pelos experimentos, pacientes, organização dos dados); Análise / interpretação (responsável pela análise estatística, avaliação e apresentação dos resultados); Levantamento da literatura (participou da pesquisa bibliográfica e levantamento de artigos); Redação (responsável por escrever uma parte substantiva do manuscrito).

Roseli Belmonte Machado - Concepção e desenvolvimento (desde a ideia para a investigação ou artigo, criou a hipótese); Desenho metodológico (planejamento dos métodos para gerar os resultados); Supervisão (responsável pela organização e execução do projeto e da escrita do manuscrito); Levantamento da literatura (participou da pesquisa bibliográfica e levantamento de artigos); Redação (responsável por escrever uma parte substantiva do manuscrito); Revisão crítica (responsável pela revisão do conteúdo intelectual do manuscrito antes da apresentação final).

Denise Grosso da Fonseca - Concepção e desenvolvimento (desde a ideia para a investigação ou artigo, criou a hipótese); Desenho metodológico (planejamento dos métodos para gerar os resultados); Supervisão (responsável pela organização e execução do projeto e da escrita do manuscrito); Levantamento da literatura (participou da pesquisa bibliográfica e levantamento de artigos); Redação (responsável por escrever uma parte 
substantiva do manuscrito); Revisão crítica (responsável pela revisão do conteúdo intelectual do manuscrito antes da apresentação final).

\section{REFERÊNCIAS}

ANVERSA, Ana L. B; SILVA JÚNIOR, Arestides P; BARBOSA, Ieda P. R; OLIVEIRA, Amauri A. B. A prática reflexiva na formação de professores de educação física na modalidade EaD. Porto Alegre: Revista Brasileira de Ciência e Movimento, v. 25, n. 2, p. 122-136, 2017.

BRASIL. Lei de Diretrizes e Bases da Educação Nacional 9394/1996. LDB, Brasília, 1996.

BRASIL, Secretaria da Educação Média e Tecnologia. PCN+: Ensino Médio- orientações educacionais complementares aos Parâmetros Curriculares Nacionais. Ministério da Educação, Brasília, 2002.

BRASIL. Lei de Diretrizes e Bases da Educação Nacional 10.793/2003. LDB, Brasília, 2003.

BRASIL. Base Nacional Comum Curricular. Ministério da Educação, Brasília, 2018.

BRASIL. Pesquisa Nacional por Amostra de Domicílios Contínua. Agência Brasil, 2020a. Disponível em: https://agenciabrasil.ebc.com.br/economia/noticia/2020-04/um-emcada-quatro-brasileiros-nao-tem-acesso-internet. Acesso em: 29 abr. 2020.

BRASIL. Pesquisa Nacional por Amostra de Domicílios Contínua. Agência Brasil, 2020b. Disponível em: https://agenciabrasil.ebc.com.br/economia/noticia/2020-04/celular-e-oprincipal-meio-de-acesso-internet-no-pais. Acesso em: 29 abr. 2020.

BRASIL. Conselho Nacional de Educação/Secretaria de Educação Média e Tecnológica. Parâmetros Curriculares Nacionais: Ensino Médio. Diário Oficial da União, Brasília, 2000. Disponível em: http://portal.mec.gov.br/seb/arquivos/pdf/blegais.pdf. Acesso em: 15 mar. 2020

DINO. Brasil é líder no uso de smartphones, mas título ainda não deve ser comemorado. Estado de Minas, Belo Horizonte, 07 fev. 2019. Disponível em: https://www.em.com.br/app/noticia/tecnologia/2019/02/07/interna tecnologia,1028679/ brasil-lider-uso-de-smartphones-titulo-ainda-nao-deve-ser-comemorado.shtml. Acesso em: 30 abr. 2020.

E-DOCENTE. O desafio do desenvolvimento das competências e habilidades propostas pela BNCC, em tempos de educação remota. E-Docente. 16 set. 2020. Disponível em: https://www.edocente.com.br/blog/2020/09/16/desafio-desenvolvimento-dascompetencias-e-habilidades-bncc-em-educacaoremota/\# : : text=Segundo\%20a\%200NU\%20(Organiza\%C3\%A7\%C3\%A30\%20das, lon ge\%20das\%20salas\%20de\%20aula. Acesso em: 20 set. 2020.

FAZENDA, Ivani Catarina Arantes. Integração e interdisciplinaridade no ensino brasileiro: Efetividade ou ideologia. 6. ed. São Paulo: Edições Loyola, 2011.

FONSECA, Denise G; MACHADO, Roseli B; TAVARES, Natacha da S; FERNANDES, Flavia; MACHADO, Sandro; COSTA, Araton C. A Educação Física escolar na área das linguagens: aspectos curriculares, legislativos e pedagógicos. Porto Alegre: Cenários, 2015. 
FONSECA, Denise G; MACHADO, Roseli B; TAVARES, Natacha da S; MACHADO, Sandro; PUJOL, Luan; LIMA, Viviane. Matizes da Linguagem e Ressonâncias da Educação Física No Ensino Médio. Movimento, Porto Alegre, v. 23, n. 2, p. 661-674, abr./jun. de 2017.

FREIRE, Paulo. Extensão ou comunicação? Rio de Janeiro: Paz e Terra, 1977

GATTI, Bernadete; ANDRÉ, Marli. A relevância dos métodos de pesquisa qualitativa em Educação no Brasil. In: WELLER, Wivian; PFAFF, Nicolle. Metodologias da pesquisa qualitativa em Educação: teoria e prática. Petrópolis, RJ: Vozes, 2013.

GUTERRES, António. O futuro da educação está aqui. Nações Unidas. 2020. Disponível em: https://www.un.org/en/coronavirus/future-education-here. Acesso em: 26 abr. 2020.

G1. Europeus comemoram os 75 anos do fim da $2^{\circ}$ Guerra Mundial em meio à pandemia do coronavírus. Globo.com, 08 mai. 2020. Disponível em:

https://g1.globo.com/mundo/noticia/2020/05/08/europeus-comemoram-os-75-anos-dofim-da-2a-guerra-mundial-em-meio-a-pandemia-do-coronavirus.ghtml. Acesso em: 08 mar. 2021.

LAZZAROTTI FILHO, Ari; CRUVINEL, Fernanda; SILVA, Ana M; SILVA, Margarete Z; Almeida, GUENTHER C. F. A dinâmica, os principais problemas e as qualidades no desenvolvimento de um curso de licenciatura em educação física na modalidade à distância. Goiás: Pensar a Prática, 2015.

SARAIVA, Karla; TRAVERSINI, Clarice Salete; LOCKMANN, Kamila. A educação em tempos de COVID-19: ensino remoto e exaustão docente. Ponta Grossa: Práxis Educativa, 2020.

HIROSE, Rodrigo. Pandemia tira 1,1 milhão de alunos das salas de aula e obriga educação a se reinventar. Jornal Opção, Goiânia, 05 abr. 2020. Disponível em: https://www.jornalopcao.com.br/reportagens/pandemia-tira-11-milhao-de-alunos-dassalas-de-aula-e-obriga-educacao-a-se-reinventar-245538/. Acesso em: 26 abr. 2020.

SANTOS, Marlene de F.; MARCON, Daniel.; TRENTIN, Daiane T. Inserção da Educação Física na área de Linguagens, Códigos e suas Tecnologias. Motriz, Rio Claro, v. 18, n. 3, p. 571-580, jul./set. 2012. Disponível em:

http://www.scielo.br/pdf/motriz/v18n3/a17v18n3.pdf. Acesso em: 26 abr. 2021.

SOPRANA, Paula. Brasil tem cerca de 70 milhões de pessoas com acesso de internet precário ou inexistente. Folha de São Paulo, São Paulo, 16 mai. 2020. Disponível em: https://www1.folha.uol.com.br/mercado/2020/05/cerca-de-70-milhoes-no-brasil-temacesso-precario-a-internet-na-pandemia.shtml. Acesso em: 19 mai. 2020.

Recebido em: 13 mar. 2021

Aprovado em: 16 jun. 2021

Artigo submetido ao sistema de similaridade Turnitin $®$.

A revista Conexões utiliza a Licença Internacional Creative Commons Atribuição 4.0, preservando assim, a integridade dos artigos em ambiente de acesso aberto. 
associado/membro das seguintes instituições:

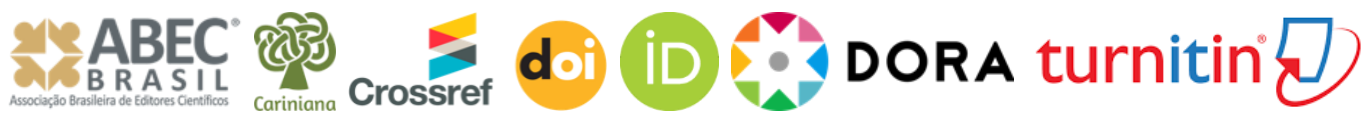

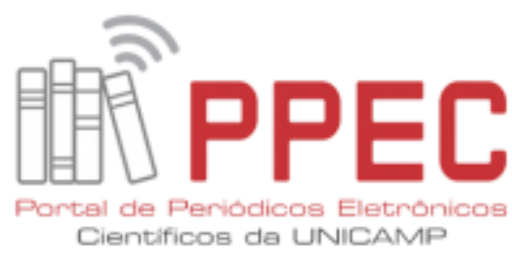

